\title{
PD-L1 Expression Confers Better Prognosis in Locally Advanced Oral Squamous Cell Carcinoma
}

\author{
YASUNAO KOGASHIWA ${ }^{1}$, MASANORI YASUDA ${ }^{2}$, HIROYUKI SAKURAI $^{3}$, MITSUHIKO NAKAHIRA $^{1}$, \\ YOSHIE SANO $^{1}$, KENJI GONDA ${ }^{4}$, TETSUYA IKEDA ${ }^{5}$, HITOSHI INOUE ${ }^{1}$, KIYOMI KUBA ${ }^{1}$, \\ SUSUMU OBA ${ }^{1}$, JUNICHI ISHIKAWA ${ }^{1}$, YUICHIRO ENOKI ${ }^{1}$, SATOKO MATSUMURA $^{1}$, \\ KAZUHIKO MINAMI ${ }^{1}$, YASUHIRO EBIHARA ${ }^{1}$ and MASASHI SUGASAWA ${ }^{1}$ \\ Departments of ${ }^{1}$ Head and Neck Surgery, and Otolaryngology, and \\ ${ }^{2}$ Pathology, Saitama Medical University International Medical Center, Hidaka, Japan; \\ Departments of ${ }^{3}$ Pharmacology and Toxicology, and ${ }^{5}$ Otolaryngology, Head and Neck Surgery, \\ Kyorin University School of Medicine, Mitaka, Japan; \\ ${ }^{4}$ Department of Surgery, Japan Community Health Care Organization, Nihonmatsu, Japan
}

\begin{abstract}
Background/Aim: Clinical trials with therapies targeting immune checkpoint molecules have shown promising results in several tumor types. However, the predictive and prognostic values of these immunological factors for locally advanced oral squamous cell carcinomas (LAOSCC) remain unclear. Our purpose was to evaluate the expression and prognostic value of programmed cell deathligand $1(P D-L 1)$ and $P D-L 2$ and to correlate their expression with the degree of infiltration by $C D 8^{+}$cells in LAOSCC. Patients and Methods: A total of 84 patients with LAOSCC were included. PD-L1, PD-L2 and CD8 expression was detected in the tumor tissue using immunohistochemistry and was tested for correlation with clinical outcome. Results: PD$L 1$ and PD-L2 were expressed in 52.4\% and 23.8\% of LAOSCC cases, respectively. $P D-L 1$ positivity was significantly associated with superior disease-free $(p=0.024)$ and overall $(p=0.008)$ survival of the patients and retained significance in multivariate analysis. $P D-L 1$ positivity was correlated with CD8 density. Conclusion: PD-L1 expression was associated with $C D 8^{+}$tumor-infiltrating lymphocytes and better outcome in patients with LAOSCC.
\end{abstract}

The recent demonstration that blockade of the programmed cell death-1/-ligand 1 (PD-1/PD-L1) or PD-L2 checkpoint pathway

\footnotetext{
Correspondence to: Yasunao Kogashiwa, Department of Head and Neck Surgery, Otolaryngology, Saitama Medical University International Medical Center, Yamane 1397-1, Hidaka, Saitama 350-1298, Japan. Tel: +81 42-9844111, e-mail: y_koga@saitamamed.ac.jp
}

Key Words: PD-L1, PD-L2, immune checkpoint, prognosis, head and neck cancer. is effective against several cancer types, including melanoma (1) and non-small cell lung cancer (2), has led to the clinical testing of inhibitors of PD-1 and its ligands in head and neck squamous cell cancers (HNSCC) (3). Immune check points such as PD-1 are manipulated by tumors to allow tumor growth that is unchecked by the immune system. Overexpression of PD-L1 by tumor cells activates the PD-1 and its ligands checkpoint pathway, by binding to the PD-1 receptor, and attenuating the immune response. The binding of antibodies targeting immune checkpoints such the binding of PD-1 to its ligands can 'release the brakes' and induce an immune response against the tumor. Solid cancers are infiltrated to varying degrees by immune cells [tumor-infiltrating lymphocytes (TILs)], and this phenomenon was suggested to be a manifestation of the host immune response against cancer cells (4). Given that PD-1 ligands on tumor cells interact with TILs in the tumor microenvironment, a comprehensive analysis of molecules related to PD- 1 and its ligands might provide invaluable information for determination of the biological and clinical relevance of this pathway for head and neck cancer.

The present study aimed to evaluate the prognostic significance of PD-L1 and PD-L2 expression and their correlation with TILs in locally advanced oral squamous cell carcinoma (OSCC).

\section{Patients and Methods}

A total of 84 patients with primary advanced OSCC who underwent surgical resection at the Saitama Medical School International Medical Center (Saitama, Japan) from April 2007 to December 2014 were included in this study. Patients who had received induction chemotherapy or radiotherapy for the head and neck region before surgery or who exhibited distant metastasis at the time of diagnosis were excluded. This study was approved by the Institutional Review Board of Saitama Medical School International Medical Center (14-192). 
Immunohistochemistry (IHC) of PD-L1, PD-L2 and CD8. IHC was performed to estimate the expression of PD-L1 and PD-L2, and the presence of CD8+ TILs in tumor samples. Tumor sections were deparaffinized with xylol and dehydrated in an alcohol series. The sections were washed in hydrogen peroxide, followed by distilled water washes. The slides were then subjected to heat-induced antigen retrieval using EDTA buffer ( $\mathrm{pH} \mathrm{9.0)} \mathrm{at} 100^{\circ} \mathrm{C}$ for $20 \mathrm{~min}$, and were then washed in distilled water. Subsequently, the slides were incubated in a moist chamber, with the following specific primary antibodies: A rabbit monoclonal antibody to PD-L1 (clone SP142; Spring Bioscience, Pleasanton, CA, USA), a rabbit polyclonal antibody to PD-L2(clone 80380; Sigma-Aldrich, Missouri, St. Louis, MO, USA), and a mouse monoclonal antibody to $\mathrm{CD} 8$ (clone $\mathrm{C} 8 / 144 \mathrm{~B}$; Thermofisher Scientific, Waltham, MA, USA), at $4^{\circ} \mathrm{C}$ overnight. The antibodies were diluted as follows: anti-PD-L1 and anti-CD8, 1:100; anti-PD-L2 1:10. The slides were then washed in phosphate-buffered saline (PBS), pH 7.4. The slides were subsequently incubated with primary anti-mouse or anti-rabbit antibody, followed by incubation with the labeled polymer, Envision ${ }^{\mathrm{TM}}+$ Dual Link System-HRP (DAKO, Santa Clara, CA, USA) using two sequential 30-min incubations. Staining was completed with a $5-10 \mathrm{~min}$ incubation with3,3'-diaminobenzidine (DAB)+ substrate-chromogen (DAKO). Finally, the slides were washed in tap water, counterstained with hematoxylin for $30 \mathrm{~s}$, dehydrated and mounted.

PD-L1 positivity of specimens was defined based on a $5 \%$ expression threshold, according to reported clinical studies $(1,5)$. The threshold of PD-L2 expression was defined as for PD-L1 for descriptive purposes. The number of TILs $\left(\mathrm{CD} 8^{+}\right.$cells) was counted in at least four different high-power fields (hpf; $\times 40$ objective, $\times 10$ eyepiece) for each specimen. Fields with the most abundant TILs in a specimen were selected for counting. The average number of TILs of all specimens was used as the threshold level for determination of high or low TIL frequency for each specimen.

Statistical analysis. All statistical analyses were performed with EZR (Saitama Medical Center, Jichi Medical University, Saitama, Japan), which is a graphical user interface for $R$ (The $R$ Foundation for Statistical Computing, Vienna, Austria, ver. 2.13.0). More precisely, it is a modified version of $\mathrm{R}$ commander (ver. 1.6-3) designed to add statistical functions frequently used in biostatistics (6). Correlations between PD-L1 or PD-L2 expression and patient characteristics were analyzed using the chi-squared or Fisher's exact test for categorical variables. Overall survival (OS) and progression-free survival (PFS) were calculated by the Kaplan-Meier method; differences were assessed by a log-rank test. We performed univariate analyses using the Cox proportional hazards regression model to identify prognostic factors associated with OS and PFS, which were then considered in a multivariate Cox proportional hazards regression analysis. All $p$-values were two sided and $p$-values of 0.05 or less were considered statistically significant.

\section{Results}

Clinicopathological characteristics of the patients. Eightyfour patients (57 males (67.9\%) and 27 females (32.1\%)) were retrospectively included in the study. The median age of the patients at diagnosis was 68 years (range $=20-92$ years). The mean duration of follow-up was 40.6 months,
Table I. Clinicopathological characteristics of patients.

\begin{tabular}{lc}
\hline Characteristic & Value \\
\hline Age, years & \\
Median & 68 \\
Range & $20-92$ \\
Gender, $\mathrm{n}$ & \\
Male & 57 \\
Female & 27 \\
Follow-up period, months & \\
Median & 40.6 \\
Range & $3.8-89.6$ \\
Smoking status, $\mathrm{n}$ & \\
Never-smoker & 33 \\
Smoker & 39 \\
Unknown & 12 \\
Performance status, $\mathrm{n}$ & \\
0 & 56 \\
1 & 24 \\
2 & 4 \\
Clinical stage, $\mathrm{n}$ & \\
III & 13 \\
IVA & 71 \\
Subsite, $\mathrm{n}$ & \\
Cheek lining & 5 \\
Gingiva & 31 \\
Hard palate & 4 \\
Tongue & 32 \\
Floor of mouth & 12 \\
\hline
\end{tabular}

with a range of 3.8-89.6 months. Thirteen patients (15.5\%) had stage III disease and 71 patients $(84.5 \%)$ had stage IVA disease at the time of diagnosis. Tumor subsites and patient characteristics are shown in Table I.

The expression of $P D-L 1$ and $P D-L 2$ and infiltration of $C D 8^{+}$TILs in locally advanced OSCC. Immunostaining of PD-L1 and PD-L2 was observed in the membrane or cytoplasm of tumor cells and stromal lymphocytes. Representative images of IHC staining of PD-L1, PD-L2 and CD8 are presented in Figure 1A-C, respectively. Expression of PD-L1 and PD-L2 was positive in 52.4\% and $23.8 \%$ of tumors, respectively (Table II). PD-L1 expression was not significantly correlated with PD-L2 expression (Spearman's rank correlation; $r=0.141, p=0.2$ ). The number of TILs ranged from 0 to 353 per hpf (average 83/hpf TILs). We therefore divided the tumors into two groups based on the number of $\mathrm{CD} 8^{+}$TILs: a group with high TIL frequency , which had more than 83 TILs, and a group with low TIL frequency, with fewer than 83 TILs.

Comparative analysis of $P D-L 1$ and $P D-L 2$ expression and $\mathrm{CD}^{+}$TILs, and their association with clinicopathological characteristics in locally advanced 

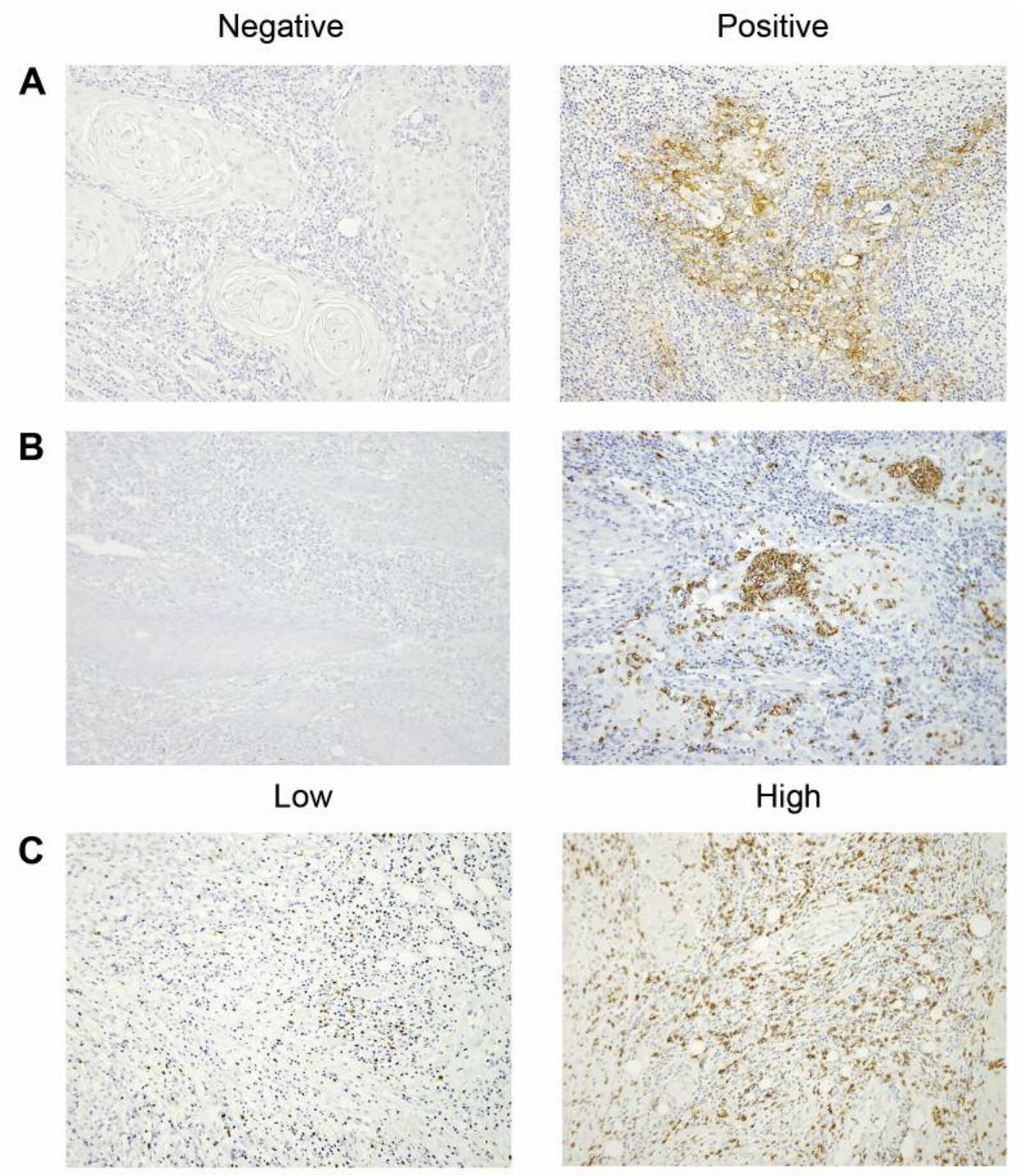

Figure 1. Representative expression patterns of programmed cell death-ligand1 (PD-L1), PD-L2, and CD8 in advanced oral squamous cell carcinomas (SCC) samples. Representative negative and positive staining of samples of advanced oral SCC for PD-L1 (A) and PD-L2 (B), and CD8 staining of samples with low and high numbers of CD8+ tumor-infiltrating lymphocytes (TILs) (C) are shown. The number of CD8+ TILs was counted using at least four different high-power fields $(\times 40$ objective $\times 10$ eyepiece $)$ that contained the highest level of TILs.

OSCC. The clinicopathological characteristics of patients with advanced OSCC, grouped according to their expression of PD-L1 and PD-L2, are shown in Table II. PD-L1 positivity was significantly positively correlated with the number of TILs ( $p<0.001$, Table II and Figure 2). In contrast, no significant relationship between PD-L2 expression and the number of TILs was detected. Moreover, significantly positive correlations between PDL1 expression and recurrence $(p=0.024)$ and female sex $(p=0.010)$, and between PD-L2 and stage $(p=0.011)$ were detected (Table II).

PD-L1 expression represents an independent predictor of survival of patients with locally advanced OSCC. We next performed Kaplan-Meier and Cox proportional regression analyses to determine whether the TIL number or PD-L1/PDL2 positivity correlated with PFS or OS of patients following treatment. 
Table II. Clinicopathological characteristics of patients with oral squamous cell carcinoma, including cluster of differentiation 8-positive (CD8 $\left.{ }^{+}\right)$ tumor-infiltrating lymphocytes (TILs), according to programmed cell death-ligand 1 (PD-L1) and PD-L2 expression in tumor.

\begin{tabular}{|c|c|c|c|c|c|c|}
\hline & \multicolumn{3}{|c|}{ PD-L1 expression } & \multicolumn{3}{|c|}{ PD-L2 expression } \\
\hline & Negative & Positive & $p$-Value & Negative & Positive & $p$-Value \\
\hline Total & 40 & 44 & & 64 & 20 & \\
\hline \multicolumn{7}{|l|}{ Gender, $\mathrm{n}$} \\
\hline Female & 7 & 20 & 0.010 & 21 & 6 & 1.000 \\
\hline Male & 33 & 24 & & 43 & 14 & \\
\hline \multicolumn{7}{|l|}{ Age, years } \\
\hline$<65$ & 15 & 13 & 0.492 & 22 & 6 & 0.792 \\
\hline$\geq 65$ & 25 & 31 & & 42 & 14 & \\
\hline \multicolumn{7}{|l|}{ BMI, $\mathrm{kg} / \mathrm{m}^{2}$} \\
\hline$<18$ & 7 & 6 & 0.764 & 10 & 3 & 1.000 \\
\hline$\geq 18$ & 32 & 38 & & 53 & 17 & \\
\hline \multicolumn{7}{|c|}{ Smoking history, $\mathrm{n}^{\mathrm{a}}$} \\
\hline Never smoker & 12 & 21 & 0.103 & 29 & 4 & 0.0508 \\
\hline Smoker & 22 & 17 & & 26 & 13 & \\
\hline \multicolumn{7}{|c|}{ Performance status, $n$} \\
\hline 0 & 25 & 31 & 0.492 & 45 & 11 & 0.277 \\
\hline $1 / 2$ & 15 & 13 & & 19 & 9 & \\
\hline \multicolumn{7}{|l|}{ T Stage, $\mathrm{n}$} \\
\hline $1 / 2$ & 8 & 11 & 0.613 & 13 & 6 & 0.373 \\
\hline $3 / 4$ & 32 & 33 & & 51 & 14 & \\
\hline \multicolumn{7}{|l|}{ N Stage, $n$} \\
\hline 0 & 11 & 13 & 0.734 & 20 & 4 & 0.449 \\
\hline 1 & 6 & 9 & & 10 & 5 & \\
\hline 2 & 23 & 22 & & 34 & 11 & \\
\hline \multicolumn{7}{|l|}{ Stage, $\mathrm{n}$} \\
\hline III & 4 & 9 & 0.235 & 6 & 7 & 0.011 \\
\hline IV & 36 & 35 & & 58 & 13 & \\
\hline \multicolumn{7}{|l|}{ Recurrence, $\mathrm{n}$} \\
\hline No & 22 & 33 & 0.024 & 42 & 13 & 0.866 \\
\hline $\mathrm{L} / \mathrm{R}$ & 6 & 8 & & 10 & 4 & \\
\hline Distant & 12 & 3 & & 12 & 3 & \\
\hline \multicolumn{7}{|l|}{ PORT/POCRT, n } \\
\hline Yes & 20 & 16 & 0.271 & 26 & 16 & 0.605 \\
\hline No & 20 & 28 & & 38 & 10 & \\
\hline \multicolumn{7}{|l|}{ CD8 ${ }^{+}$TILs, $\mathrm{n}$} \\
\hline Low & 29 & 13 & $<0.001$ & 33 & 9 & 0.798 \\
\hline High & 11 & 31 & & 31 & 11 & \\
\hline
\end{tabular}

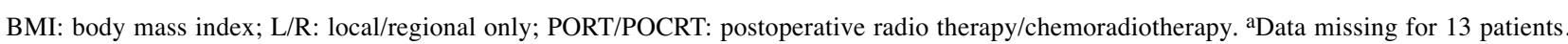

Kaplan-Meier curves showed significantly poorer PFS and OS of patients with PD-L1-negative tumors compared to those with PD-L1-positive ones ( $p=0.024$, and $p=0.008$, respectively). No significant differences in PFS and OS according to PD-L2 status were found. Such survival analysis also demonstrated that the number of TILs was not correlated with PFS or OS (log rank test: $p=0.35$, and $p=0.058$, respectively) (Figure 3). Univariate analysis (Cox regression model) showed that two variables, $\mathrm{cN} 2$ and PD-L1 positivity, were significantly correlated with PFS and OS (Table III). Multivariate analyses (Cox regression model) for PFS and OS of these factors showed that $\mathrm{cN} 2(p=0.0324$ and $p=0.010$, respectively) and PD-L1 positivity ( $p=0.0315$ and $p=0.008$, respectively) were significantly correlated with PFS and OS (Table III).

Finally, we performed sub-group analysis to examine the association of TIL frequency with PD-L1 expression, and its relationship with prognosis. We divided the tumors into four groups based on their positive or negative PD-L1 expression and on their high or low TIL frequency. The PD-L1-positive group with high TIL frequency displayed a tendency towards prolonged survival, whereas the PD-L1-negative group with high TIL frequency displayed a tendency towards shorter survival, although this tendency was not statistically significant ( $p=0.672$, Figure 4$)$. 

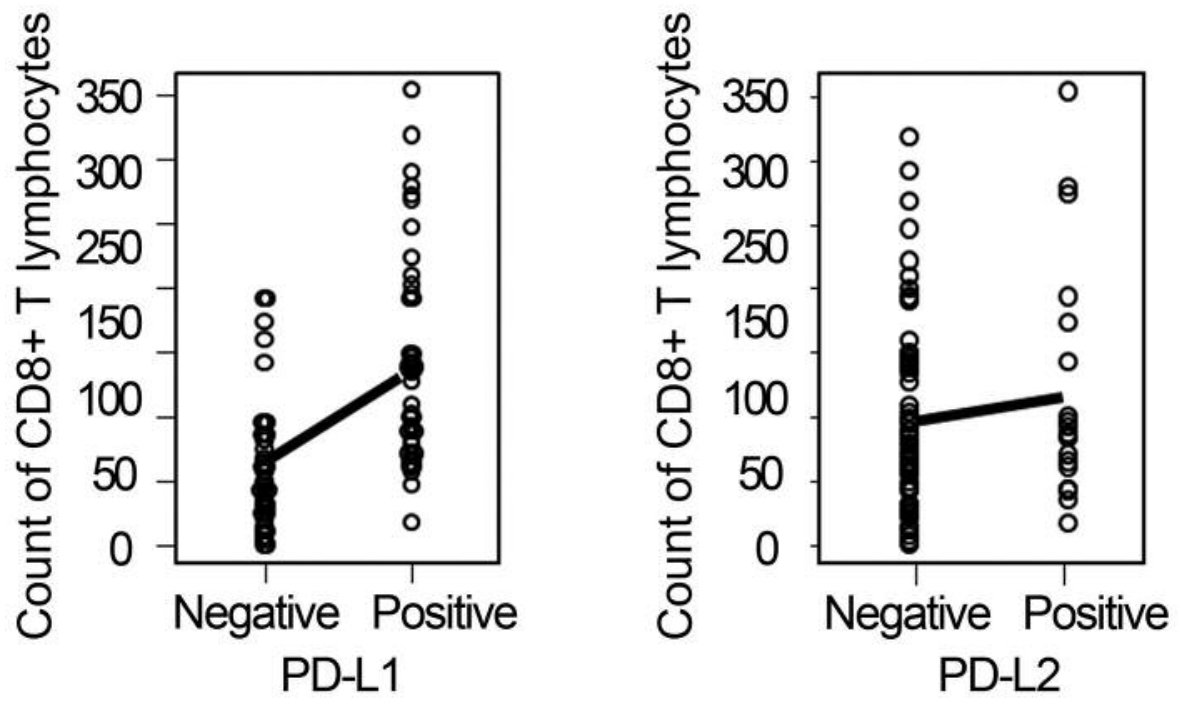

Figure 2. Correlation of programmed cell death-ligand1 (PD-L1) and PD-L2 expression and the number of CD8+ tumor-infiltrating lymphocytes (TILs). The CD8+ count was determined in PD-L1- and PD-L2-negative and-positive samples. The number of CD8+ TILs was significantly positively correlated with PD-L1 expression (A) (Spearman's rho=0.574, $p<0.001$ ), but not with PD-L2 expression (B) (Spearman's rho=0.0818, $p=0.459$ ).

\section{Discussion}

Although blockade of the PD-1 and PD-L1/PD-L2 pathway with monoclonal antibodies has recently emerged as a new therapeutic modality for head and neck cancer, the association between PD-L1 expression and prognosis in advanced HNSCC has remained largely controversial (7-9). In the present study, we examined PD-L1 and PD-L2 expression using IHC in patients with locally advanced OSCC who had undergone surgery, and found that patients who had positive expression of PD-L1 had significantly better survival than patients who were negative for PD-L1. Our results are not in agreement with previous studies that demonstrated an adverse prognostic effect of PD-L1 expression assessed by IHC in several cancer types including renal, colorectal and lung cancer (10-12). However, other studies in metastatic melanoma, non-small cell lung cancer, Merkel cell carcinoma, and laryngeal cancer, demonstrated a positive association of high PD-L1 expression and increased TIL frequency with longer survival $(8,13-15)$.

We also found a significant positive association between PD-L1 expression and the frequency of TILs. PD-L1 expression was reported to be up-regulated by $\mathrm{CD} 8^{+}$cell secretion of interferon gamma (IFN- $\gamma$ ) and patients with melanoma with TIL-rich tumors expressing PD-L1 are likely to have better immune surveillance (13). The prognostic importance of tumor infiltration with CD8+ cells has been demonstrated in breast, esophageal, lung, ovarian, colon, anal, and head and neck cancer $(16,17)$. Tumeh et al. also demonstrated that the location of infiltrating $\mathrm{CD}^{+}$cells and PD-L1-expressing cells within a tumor specimen is of particular importance; detection of $\mathrm{CD}^{+}$TILs and PD-L1expressing cells at the invasive margin was associated with better response to therapy in melanoma (18). This finding suggests that $\mathrm{CD}^{+}$TILs have a crucial role in killing tumor cells when the PD-1/PD-L1 pathway is blocked. In our cases, the PD-1/PD-L1 pathway might have been blocked after surgery because almost all of the PD-L1 that was present in the local site was resected with the tumor. On the other hand, $\mathrm{CD}^{+}$TILs around the tumor were likely to remain at the local site after tumor resection. We speculate that the number of $\mathrm{CD}^{+}$TILs is increased in PD-L1-positive cases, and that the increase in CD8 ${ }^{+}$TILs was the reason why patients with PD-L1-positive tumors had a good prognosis.

Since PD-L1 positivity indicates the presence of higher numbers of TILs, anti-PD-1/PD-L1 therapy against such locally advanced OSCC would be effective via TILs. Consistent with this possibility, PD-L1 expression has been reported to be the most important predictor of the responsiveness of various cancer types to PD-L1 or PD-1 blocking antibodies $(2,19,20)$.

It has already been shown that patients with HNSCC whose tumors contained infiltrating $\mathrm{CD}^{+}$TILs had better survival than those without TILs (8). Interestingly, in our study, PDL1 positivity conferred a tendency for a more favorable influence on survival when high numbers of TILs were present in the specimen compared to when low numbers of TILs were present (Figure 4). These results together with our correlation study between PD-L1 positivity and numbers of TILs (Figure 2) suggest that PD-L1 may be a marker for the presence of TILs. In fact, TILs have been reported to stimulate PD-L1 

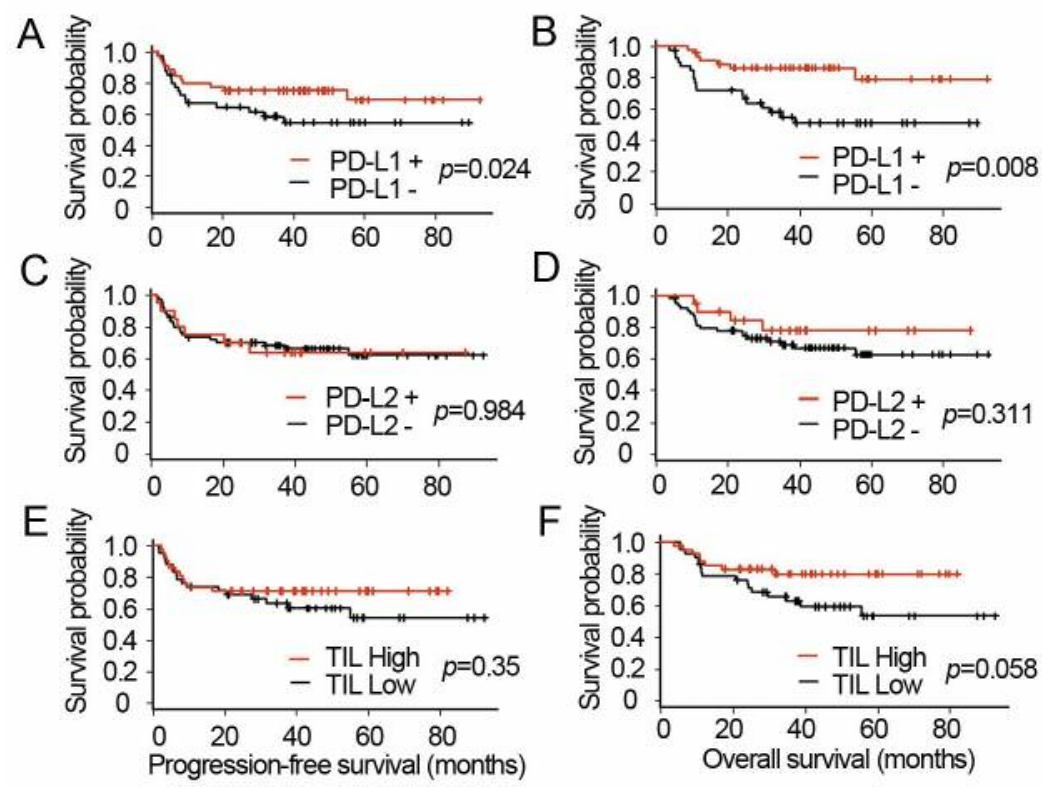

Figure 3. Correlation of programmed cell death-ligand1 (PD-L1) and PD-L2 expression and the number of CD8+ tumor-infiltrating lymphocytes (TILs) with survival. Kaplan-Meier curves for analysis of the effect of PD-L1 expression $(A, B), P D-L 2$ expression $(C, D)$ and the number of CD8+ $C T L s(E, F)$ in tumor samples of patients with locally advanced oral squamous cell carcinomas on progression free survival (PFS) (A, C, E) and overall survival $(O S)(B, D, F)$ are shown. p-Values were calculated using a log-rank test.

production by secreting IFN- $\gamma$ in melanoma (13). In our study, there were 14 patients whose tumors were PD-L1-positive but which had low numbers of TILs (Figure 4). In such cases, PDL1 expression is likely to be driven by pathways other than the IFN- $\gamma$ pathway. The phosphoinositide 3-kinasel/mitogenactivated protein kinase and zinc finger E-box-binding homeobox 1/miR-200 pathways have been reported to stimulate PD-L1 expression $(21,22)$. It is possible that the prognostic significance of PD-L1 may not be clear when PD$\mathrm{L} 1$ expression is not driven by $\mathrm{CD}^{+}$cell-derived IFN- $\gamma$.

Our retrospective study had several limitations. Firstly, the sample size was relatively small. Secondly, PD-L1 and PDL2 expression was evaluated using the antibodies of clone SP142 and clone 80380, respectively. There are many antibody clones for detection of PD-L1 and PD-L2, and it remains unclear which clones are the best for evaluation of the expression status of PD-L1 and PD-L2. Thirdly, positivity of PD-L1 and PD-L2 expression was determined based on a $5 \%$ expression threshold but this threshold is also controversial. Further studies are warranted to standardize the method of assessment of PD-L1 and PD-L2 expression by IHC in larger samples in head and neck cancer.

In conclusion, our study demonstrated that PD-L1 and PD-L2 were expressed in approximately half and onequarter, respectively, of patients with locally advanced OSCC. Moreover, the expression of PD-L1 was positively associated with the frequency of TILs and better survival.

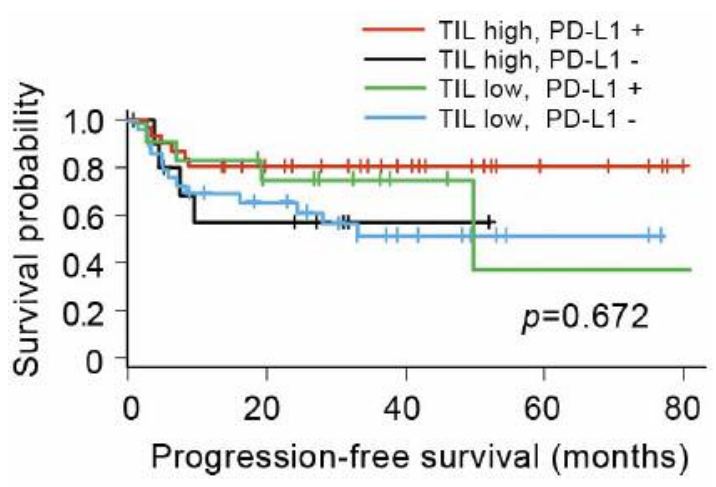

Figure 4. Kaplan-Meier curves of progression-free survival (PFS) of subgroups of patients with locally advanced oral squamous cell carcinomas grouped according to $C D 8^{+}$count and programmed cell death-ligand1 (PD-L1) expression status. The p-value was calculated using a log-rank test. The CD8-high/PD-L1-positive group displayed a tendency towards better PFS than the other groups and the CD8-low, PD-L1-positive group displayed a tendency towards worse PFS than the other groups, although the differences between the groups were not significant.

\section{Conflicts of Interest}

The Authors declare that there is no conflict of interest in regard to this study. 
Kogashiwa et al: PD-L1 Expression Confers Better Prognosis in Locally Advanced OSCC

Table III. Univariate and multivariate analyses of parameters associated with overall (OS) and progression free (PFS) survival.

\begin{tabular}{|c|c|c|c|c|c|c|c|c|c|c|c|c|}
\hline \multirow[b]{3}{*}{ Parameter } & \multicolumn{6}{|c|}{ OS } & \multicolumn{6}{|c|}{ PFS } \\
\hline & \multicolumn{3}{|c|}{ Univariate analysis } & \multicolumn{3}{|c|}{ Multivariate analysis } & \multicolumn{3}{|c|}{ Univariate analysis } & \multicolumn{3}{|c|}{ Multivariate analysis } \\
\hline & HR & $95 \% \mathrm{CI}$ & $p$-Value & HR & $95 \%$ CI & $p$-Value & HR & $95 \% \mathrm{CI}$ & $p$-Value & HR & $95 \% \mathrm{CI}$ & $p$-Value \\
\hline$\geq 65$ years old & 1.36 & $0.569-3.27$ & 0.487 & & & & 0.975 & $0.452-2.10$ & 0.950 & & & \\
\hline Female gender & 1.65 & $0.659-4.13$ & 0.285 & & & & 1.10 & $0.504-2.43$ & 0.797 & & & \\
\hline BMI & 0.521 & $0.193-1.40$ & 0.197 & & & & 0.706 & $0.268-1.85$ & 0.480 & & & \\
\hline Smoker & 0.857 & $0.543-1.36$ & 0.511 & & & & 0.691 & $0.307-1.55$ & 0.373 & & & \\
\hline cT3/4 & 1.55 & $0.532-4.55$ & 0.420 & & & & 2.94 & $0.890-9.73$ & 0.0766 & & & \\
\hline $\mathrm{cN} 2$ & 2.35 & $1.35-9.72$ & 0.011 & 3.66 & $1.36-9.86$ & 0.010 & 2.45 & $1.08-5.54$ & 0.0313 & 2.439 & $1.078-5.520$ & 0.0324 \\
\hline Margin-positive & 2.09 & $0.622-7.07$ & 0.233 & & & & 1.36 & $0.411-4.52$ & 0.610 & & & \\
\hline PD-L1-positive & 0.257 & $0.102-0.649$ & 0.006 & 0.256 & $0.101-0.646$ & 0.008 & 0.576 & $0.274-0.956$ & 0.0372 & 0.541 & $0.278-0.894$ & 0.0315 \\
\hline PD-L2-positive & 0.442 & $0.132-1.486$ & 0.187 & & & & 1.01 & $0.431-2.37$ & 0.978 & & & \\
\hline CD8 high & 0.499 & $0.214-1.16$ & 0.109 & & & & 0.717 & $0.342-1.50$ & 0.378 & & & \\
\hline
\end{tabular}

BMI: Body mass index; PD-L1/2: programmed cell death-ligand 1/2; CD8: cluster of differentiation 8; HR: hazard ratio; CI: confidence interval.

\section{Acknowledgements}

This study was supported by a grant from Saitama Medical University International Medical Center, H26 Hidaka Project (26D-1-05) and was partly supported by a grant from Setsuro Fujii Memorial, The Osaka Foundation for Promotion of Fundamental Medical Research. The authors thank KW, NA and technicians in the Department of Pathology, Saitama Medical University International Medical Center, for their technical assistance.

\section{References}

1 Topalian SL, Hodi FS, Brahmer JR, Gettinger SN, Smith DC, McDermott DF, Powderly JD, Carvajal RD, Sosman JA, Atkins MB, Leming PD, Spigel DR, Antonia SJ, Horn L, Drake CG, Pardoll DM, Chen L, Sharfman WH, Anders RA, Taube JM, McMiller TL, Xu H, Korman AJ, Jure-Kunkel M, Agrawal S, McDonald D, Kollia GD, Gupta A, Wigginton JM and Sznol M: Safety, activity, and immune correlates of anti-PD-1 antibody in cancer. N Engl J Med 366: 2443-2454, 2012.

2 Brahmer JR: Harnessing the immune system for the treatment of non-small-cell lung cancer. J Clin Oncol 31: 1021-1028, 2013.

3 Gillison ML BG, Fayette J, Guigay J, Colevas AD and Licitra L: Nivolumav (Nivo) vs investigator's choice (IC) for recurrent or metastatic (R/M) head and neck squamous cell carcinoma (HNSCC): CheckMate 141. American Association for Cancer Research Annual Meeting 2016, April 16-20 (CT099).

4 Yu P and Fu YX: Tumor-infiltrating T lymphocytes: friends or foes? Lab Invest 86: 231-245, 2006.

5 Thompson RH, Kuntz SM, Leibovich BC, Dong H, Lohse CM, Webster WS, Sengupta S, Frank I, Parker AS, Zincke H, Blute ML, Sebo TJ, Cheville JC and Kwon ED: Tumor B7-H1 is associated with poor prognosis in renal cell carcinoma patients with long-term follow-up. Cancer Res 66: 3381-3385, 2006.

6 Kanda Y: Investigation of the freely available easy-to-use software 'EZR' for medical statistics. Bone Marrow Transplant 48: 452-458, 2013.
7 Straub M, Drecoll E, Pfarr N, Weichert W, Langer R, Hapfelmeier A, Gotz C, Wolff KD, Kolk A and Specht K: $C D 274 / P D-L 1$ gene amplification and PD-L1 protein expression are common events in squamous cell carcinoma of the oral cavity. Oncotarget 7: 12024-12034, 2016.

8 Vassilakopoulou M, Avgeris M, Velcheti V, Kotoula V, Rampias T, Chatzopoulos K, Perisanidis C, Kontos CK, Giotakis AI, Scorilas A, Rimm D, Sasaki C, Fountzilas G and Psyrri A: Evaluation of PD-L1 expression and associated tumorinfiltrating lymphocytes in laryngeal squamous cell carcinoma. Clin Cancer Res 22: 704-713, 2016.

9 Ock CY, Kim S, Keam B, Kim M, Kim TM, Kim JH, Jeon YK, Lee JS, Kwon SK, Hah JH, Kwon TK, Kim DW, Wu HG, Sung MW and Heo DS: PD-L1 expression is associated with epithelial-mesenchymal transition in head and neck squamous cell carcinoma. Oncotarget 7: 15901-15914, 2016.

$10 \mathrm{Mu}$ CY, Huang JA, Chen Y, Chen C and Zhang XG: High expression of PD-L1 in lung cancer may contribute to poor prognosis and tumor cells immune escape through suppressing tumor-infiltrating dendritic cells maturation. Med Oncol 28: 682688, 2011.

11 Song M, Chen D, Lu B, Wang C, Zhang J, Huang L, Wang $\mathrm{X}$, Timmons CL, Hu J, Liu B, Wu X, Wang L, Wang J and Liu H: PTEN loss increases PD-L1 protein expression and affects the correlation between PD-L1 expression and clinical parameters in colorectal cancer. PLoS One 8 : e65821, 2013.

12 Konishi J, Yamazaki K, Azuma M, Kinoshita I, Dosaka-Akita H and Nishimura M: B7-H1 expression on non-small cell lung cancer cells and its relationship with tumor-infiltrating lymphocytes and their PD-1 expression. Clin Cancer Res 10: 5094-5100, 2004.

13 Taube JM, Anders RA, Young GD, Xu H, Sharma R, McMiller TL, Chen S, Klein AP, Pardoll DM, Topalian SL and Chen L: Colocalization of inflammatory response with B7-H1 expression in human melanocytic lesions supports an adaptive resistance mechanism of immune escape. Sci Transl Med 4: 127ra137, 2012. 
14 Lipson EJ, Vincent JG, Loyo M, Kagohara LT, Luber BS, Wang $\mathrm{H}, \mathrm{Xu} \mathrm{H}$, Nayar SK, Wang TS, Sidransky D, Anders RA, Topalian SL and Taube JM: PD-L1 expression in the Merkel cell carcinoma microenvironment: association with inflammation, Merkel cell polyomavirus and overall survival. Cancer Immunol Res 1: 54-63, 2013.

15 Droeser RA, Hirt C, Viehl CT, Frey DM, Nebiker C, Huber X, Zlobec I, Eppenberger-Castori S, Tzankov A, Rosso R, Zuber M, Muraro MG, Amicarella F, Cremonesi E, Heberer M, Iezzi G, Lugli A, Terracciano L, Sconocchia G, Oertli D, Spagnoli GC and Tornillo L: Clinical impact of programmed cell death ligand 1 expression in colorectal cancer. Eur J Cancer 49: 2233-2242, 2013.

16 Balermpas P, Rodel F, Liberz R, Oppermann J, Wagenblast J, Ghanaati S, Harter PN, Mittelbronn M, Weiss C, Rodel C and Fokas E: Head and neck cancer relapse after chemoradiotherapy correlates with $\mathrm{CD}_{163^{+}}$macrophages in primary tumour and $\mathrm{CD}_{11 \mathrm{~b}^{+}}$myeloid cells in recurrences. Br J Cancer 111: 15091518, 2014.

17 Gooden MJ, de Bock GH, Leffers N, Daemen T and Nijman HW: The prognostic influence of tumour-infiltrating lymphocytes in cancer: a systematic review with meta-analysis. Br J Cancer 105: 93-103, 2011.

18 Tumeh PC, Harview CL, Yearley JH, Shintaku IP, Taylor EJ, Robert L, Chmielowski B, Spasic M, Henry G, Ciobanu V, West AN, Carmona M, Kivork C, Seja E, Cherry G, Gutierrez AJ, Grogan TR, Mateus C, Tomasic G, Glaspy JA, Emerson RO, Robins H, Pierce RH, Elashoff DA, Robert C and Ribas A: PD1 blockade induces responses by inhibiting adaptive immune resistance. Nature 515: 568-571, 2014.
19 Topalian SL, Drake CG and Pardoll DM: Targeting the PD-1/B7H1 (PD-L1) pathway to activate anti-tumor immunity. Curr Opin Immunol 24: 207-212, 2012.

20 Taube JM, Klein A, Brahmer JR, Xu H, Pan X, Kim JH, Chen L, Pardoll DM, Topalian SL and Anders RA: Association of PD1, PD-1 ligands, and other features of the tumor immune microenvironment with response to anti-PD-1 therapy. Clin Cancer Res 20: 5064-5074, 2014.

21 Chen L, Gibbons DL, Goswami S, Cortez MA, Ahn YH, Byers LA, Zhang X, Yi X, Dwyer D, Lin W, Diao L, Wang J, Roybal JD, Patel M, Ungewiss C, Peng D, Antonia S, Mediavilla-Varela M, Robertson G, Jones S, Suraokar M, Welsh JW, Erez B, Wistuba, II, Chen L, Peng D, Wang S, Ullrich SE, Heymach JV, Kurie JM and Qin FX: Metastasis is regulated via microRNA200/ZEB1 axis control of tumour cell PD-L1 expression and intratumoral immunosuppression. Nat Commun 5: 5241, 2014.

22 Chen J, Jiang CC, Jin L and Zhang XD: Regulation of PD-L1: a novel role of pro-survival signalling in cancer. Ann Oncol 27: 409-416, 2016. 